\title{
La enseñanza y el aprendizaje desde el enfoque de proyectos integradores para la educación turística
}

Teaching and learning from the approach of integrating projects for tourism
education

Ensino e aprendizagem na perspectiva de projetos integradores de educação em turismo

Norma Patricia Juan Vázquez

Universidad Autónoma de Chiapas, Facultad de Ciencias de la Administración C-IV,

México

normajuan_06@hotmail.com

https://orcid.org/0000-0002-2284-8905

\section{Resumen}

El objetivo de este artículo es describir una estrategia didáctica que utiliza a los proyectos integradores como articuladores de los conocimientos cognitivos y metacognitivos para asegurar el aprendizaje del estudiante. Por lo anterior, será importante determinar si las estrategias didácticas empleadas se desarrollaron en las condiciones adecuadas para la vinculación de los aprendizajes. Los proyectos integradores son una herramienta didáctica cuyo objetivo es vincular los contenidos temáticos con la práctica. En esta investigación, se tomó como objeto de estudio a la Facultad de Ciencias de la Administración C-IV de la Universidad Autónoma de Chiapas, y en específico a algunos estudiantes de la licenciatura en Gestión Turística. La mayoría de las unidades de competencias que estructuran el séptimo, sexto y tercer semestre estuvieron involucradas. A partir de un total de 136 estudiantes, de ellos $69 \%$ mujeres y $31 \%$ hombres, se formaron 26 equipos y se les dio seguimiento desde agosto del 2016 al 2018.

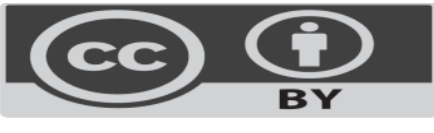




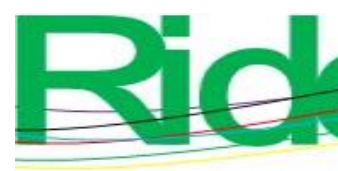

Revista Iberoamericana para la Investigación y el Desarrollo Educativo ISSN $2007-7467$

Palabras clave: aprendizaje, enseñanza, proyectos integradores.

\begin{abstract}
The objective of this article is to describe a didactic strategy that uses integrative projects as articulators of cognitive and metacognitive knowledge to ensure student learning. Therefore, it will be important to determine if the didactic strategies used were developed in the right conditions for linking learning. Integrative projects are a didactic tool whose objective is to link thematic contents with practice. In this research, the Facultad de Ciencias de la Administración C-IV of the Universidad Autónoma de Chiapas was taken as an object of study, and specifically some students of the degree in Tourism Management. Most of the competency units that structure the seventh, sixth and third semesters were involved. From a total of 136 students, of them $69 \%$ women and $31 \%$ men, 26 teams were formed and followed up from August 2016 to 2018.
\end{abstract}

Keywords: learning, teaching, integrating projects.

\title{
Resumo
}

O objetivo deste artigo é descrever uma estratégia didática que utiliza projetos integrativos como articuladores dos conhecimentos cognitivos e metacognitivos para garantir a aprendizagem dos alunos. Portanto, será importante determinar se as estratégias didáticas utilizadas foram desenvolvidas nas condições adequadas para vincular a aprendizagem. Os projetos integrativos são uma ferramenta didática cujo objetivo é relacionar os conteúdos temáticos com a prática. Nesta pesquisa, tomou-se como objeto de estudo a Faculdade de Ciências da Administração C-IV da Universidade Autônoma de Chiapas, e especificamente alguns alunos da licenciatura em Gestão de Turismo. A maioria das unidades de competência que estruturam o sétimo, sexto e terceiro semestres foram envolvidas. De um total de 136 alunos, sendo $69 \%$ mulheres e $31 \%$ homens, 26 equipes foram formadas e acompanhadas de agosto de 2016 a 2018.

Palavras-chave: aprendizagem, ensino, projetos integrativos.

Fecha Recepción: Marzo 2020

Fecha Aceptación: Octubre 2020 


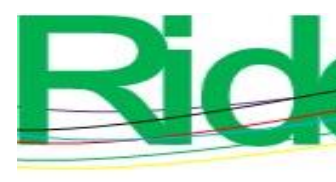

Revista Iberoamericana para la Investigación y el Desarrollo Educativo ISSN $2007-7467$

\section{Introducción}

Como maestros tenemos la labor de establecer y aplicar un modelo de enseñanzaaprendizaje fundamentado en procesos basados en su validez y no en el poder, y priorizar una relación más horizontal que vertical entre maestros y estudiantes. Fortoul (2008) afirma que "la enseñanza es la transmisión de conocimientos por parte del maestro para que los alumnos logren el aprendizaje” (p. 81). Desde aquí se visualiza la enseñanza como función del maestro; aprender será la tarea del alumno. Durante mucho tiempo este modelo de concebir a la enseñanza ha sido usado, y el impacto en la formación cognitiva en muchas generaciones ha sido reconocida, pero, recientemente, ha pasado a ser muy cuestionada. La enseñanza en nuestro siglo busca que el profesor sea un facilitador de los medios necesarios y el estudiante construya sus significados de acuerdo con sus contextos.

Al construir los procesos de aprendizaje, el maestro debe ser capaz de utilizar modalidades para la enseñanza adecuadas a las necesidades de los estudiantes con procedencias sociales y entornos culturales diferentes. En esa línea, debemos reconocer que los estudiantes poseen modos de aprender únicos. Por ello, hay que asumir una práctica pedagógica que propicie la reflexión para un cambio didáctico y para que la integración entre los procesos de enseñanza y los de aprendizaje sea más efectiva. Según Hunt (citado en Terrádez, 2007), los estilos de aprendizaje describen las condiciones o identifican la estructura sobre la cual un alumno aprende de mejor manera. Sandoval (2005) menciona que el aprendizaje es estratégico cuando se dispone de recursos metacognitivos para regularlo. Mientras que Hernández y Martínez (2008) afirman que cuando el aprendizaje se centra en los resultados y competencias adquiridas es más colectivo, activo y autorregulado. Bandura (1977), por último, señala que el aprendizaje está determinado por tres elementos: factores personales, ambiente y conducta, los cuales interactúan de manera cíclica.

Atendiendo todos estos preceptos, la Universidad Autónoma de Chiapas [Unach] (2010) implementó, luego de casi una década de iniciado el siglo XXI, una serie de estrategias de vinculación entre la sociedad y la organización educativa en cuestión. Entre ellas, se encontraban las unidades de vinculación docente (UVD), las cuales fueron concebidas como “instrumentos de aprendizaje flexibles que permiten adaptar los contenidos temáticos de los planes de estudio a las problemáticas del desarrollo económico, social y cultural; enriqueciendo los currícula e impactando en los fenómenos sociales y dinamizando las funciones sustantivas (Estrada, 2009)" (Unach, 2010, p. 26). Bajo la óptica de las UVD, el 

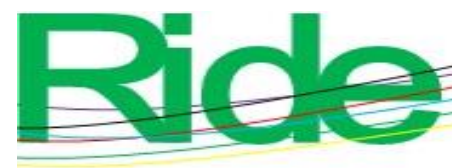

Revista Iberoamericana para la Investigación y el Desarrollo Educativo ISSN 2007 - 7467

Por requerimientos de los organismos evaluadores y acreditadores del país, en el 2015 se emprendió una nueva reestructuración del modelo educativo y académico de la Unach. Fue un trabajo realizado en conjunto con la comunidad universitaria. Docentes, estudiantes, administrativos y opiniones externas de empresarios y expertos en la materia pedagógica permitieron establecer los nuevos escenarios de los procesos de enseñanza-aprendizaje. Este trabajo concluyó en el 2019 y fue aprobado por el Consejo Universitario en enero del 2020. El objetivo ahora se centró en generar sinergias entre las estructuras curriculares y los procesos académicos para mejorar la calidad educativa y consolidar las comunidades de aprendizaje. Las siguientes son las principales características que lo definen:

- $\quad$ Centrado en el aprendizaje.

- $\quad$ Enfoque por competencias.

- Tecnologías del aprendizaje y el conocimiento.

- $\quad$ Flexibilidad.

- $\quad$ Responsabilidad social universitaria (RSU).

- Innovación.

- Internacionalización.

Nuevamente, se incorporan herramientas didácticas a la labor docente y son retomados los proyectos integradores a partir del enfoque de competencias genéricas y disciplinares. Como una forma de aprendizaje más autónomo y autorregulado, el estudiante procesa los contenidos, se los apropia y genera nuevos esquemas de pensamiento y acción dentro de su plan semestral.

La importancia de documentar esta experiencia docente tiene el objetivo, además de caracterizarla como estrategia didáctica, de difundirla entre los maestros de la facultad, debido a que los resultados obtenidos hacen que el aprendizaje del estudiante sea más práctico. 


\section{Método}

La investigación tiene un enfoque cualitativo y es de carácter descriptivo. Con la meta de integrar un portafolio de evidencia, se indagó la opinión del estudiante sobre la implementación de la enseñanza a través de los proyectos integradores; más aún, con la intención de detallar el proceso de aprendizaje, se describieron todas las dimensiones didácticas y metodológicas que se diseñaron. Así pues, se aplicó un cuestionario de 15 ítems a 136 estudiantes de la licenciatura en Gestión Turística (LGT) de la Unach. Las preguntas fueron abiertas, cerradas y de opción múltiple. Los temas se centraron en la perspectiva de aprendizaje que tiene el estudiante sobre las asignaturas, los recursos didácticos utilizados, la metodología implementada, el tiempo de trabajo, actividades desarrolladas, producto de trabajo obtenido y sobre cuál era su opinión para mejorar los procesos una vez ya vivenciados.

El estudio constituyó la labor de dos años (2016-2018). Los proyectos que se implementaron fueron de tipo semidirigido y abierto (el profesor interviene para guiar el proceso en momentos relevantes; además, se definieron pautas de trabajo; los estudiantes señalaron especificaciones para el desarrollo de sus actividades). El alcance del estudio fue transversal. Como ya se mencionó, se inició en agosto del 2016, donde se trabajó únicamente con los alumnos de séptimo semestre; en 2017, fueron los dos periodos (enero-junio, agostodiciembre), con sexto y séptimo semestres, y en el 2018, en agosto, se incorporó a los discentes de primer semestre y tercer semestre.

Tabla 1. Población muestra

\begin{tabular}{|l|l|c|}
\hline Año & Semestre & Número de estudiantes \\
\hline 2016 & $7 .^{\circ}$ LGT & 25 \\
\hline 2017 & $7 .^{\circ} \mathrm{y} 6 .^{\circ}$ LGT. & 22,27 \\
\hline 2018 & $1 .^{\circ}$ y $3 .^{\circ}$ LGT & 30,32 \\
\hline
\end{tabular}

Fuente: Elaboración propia

La elección de hacer el estudio con los estudiantes de LGT se debe a que, a diferencia de las otras licenciaturas de la Facultad de Ciencias de la Administración C-IV, inician su proceso de prácticas a partir del tercer semestre, por tener características propias de ser más activos, creativos y acostumbrados a desarrollar trabajos fuera del ámbito escolar. La licenciatura tiene gran demanda. Y se ha observado que al término de sus prácticas de 

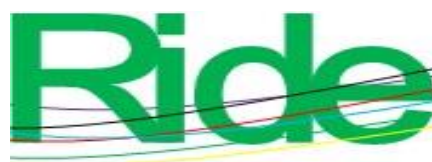

Revista Iberoamericana para la Investigación y el Desarrollo Educativo

ISSN 2007 - 7467

especialización suelen incorporarse de manera inmediata al campo laboral, por la diversidad de empresas que existen dedicadas a la actividad turística, debido a que la ciudad colinda con el mercado centroamericano y cuenta con gran afluencia turística de tipo comercial, destino de playas y montañas y un aeropuerto internacional. A nivel nacional, el turismo es la tercera fuente de ingreso de divisas, genera empleos directos e indirectos, debido a la gran diversidad de ecosistemas y patrimonio cultural mexicanos. De acuerdo con la Secretaría de Turismo [Sectur] (2018), la llegada de turistas internacionales al país fue de 41.4 millones y de nacionales 60875000 turistas. En esa misma línea, la Organización Mundial del Turismo [OMT] (2018) informó que México figura entre el ranking de los 10 países con mayor afluencia turística internacional.

Para el desarrollo de estos proyectos integradores se utilizó la metodología sintetizada en la figura 2, fruto de una serie de reuniones de planeación didáctica.

Figura 2. Planeación didáctica

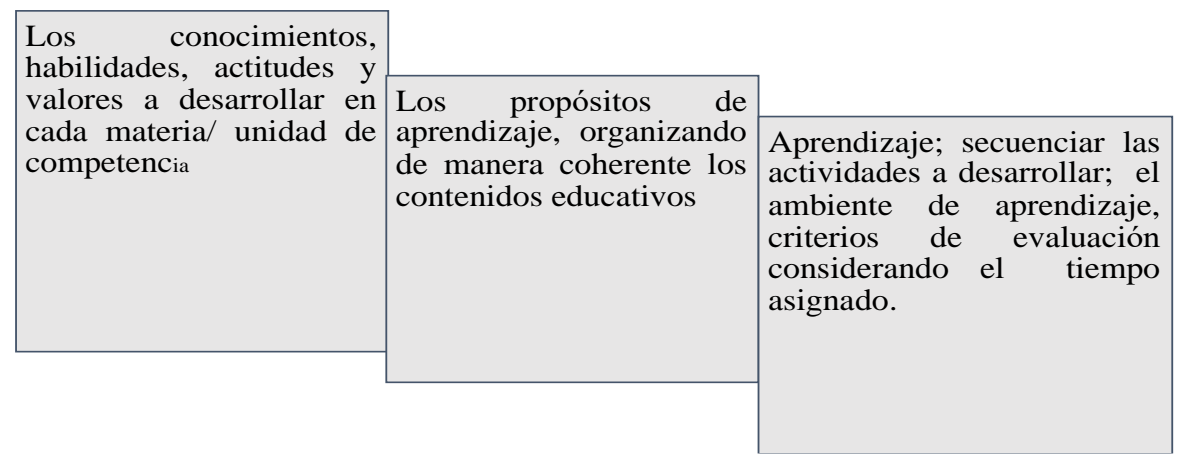

Fuente: Elaboración propia

En la tabla 2, por su parte, se muestran los esquemas de trabajo que integraron los proyectos del primer y tercer semestre, y también los objetivos de aprendizaje. 


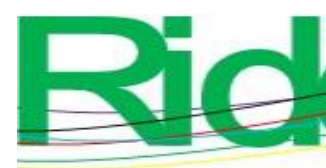

Revista Iberoamericana para la Investigación y el Desarrollo Educativo ISSN 2007 - 7467

Tabla 2. Esquema de trabajo desarrollado en primer y tercer semestre

\begin{tabular}{|c|c|}
\hline Objetivo & $\begin{array}{l}\text { Búsqueda de información, argumentación y la } \\
\text { elaboración de un diagnóstico descriptivo. }\end{array}$ \\
\hline $\begin{array}{llll}\text { Materias involucradas } & \text { en } & \text { el } \\
\text { proyecto } & & & \\
\end{array}$ & $\begin{array}{l}\text { 1. }{ }^{\circ} \text { semestre: configuración administrativa de las } \\
\text { organizaciones, metodología de la investigación, } \\
\text { caracterización del turismo. } \\
3 .^{\circ} \text { semestre: marco del liderazgo en las } \\
\text { organizaciones, animación y recreación en el } \\
\text { turismo, caracterización de la mercadotecnia, } \\
\text { identificación de los atractivos turísticos. }\end{array}$ \\
\hline Objeto de estudio & $\begin{array}{l}\text { Empresas e instituciones relacionadas con } \\
\text { actividad turística, vinculación con hoteles, } \\
\text { restaurantes y agencias de viaje de la localidad } \\
\text { seleccionada por los docentes. Para investigar } \\
\text { temas vistos en clases de acuerdo con la tira de } \\
\text { materias. }\end{array}$ \\
\hline Temas para investigar & $\begin{array}{l}\text { 1. }{ }^{\circ} \text { semestre: estructuras administrativas de las } \\
\text { empresas turísticas, a través de un planteamiento } \\
\text { del problema, marco teórico, método, resultados y } \\
\text { conclusiones. } \\
3 .^{\circ} \text { semestre: características, tipos, modelos de } \\
\text { liderazgo en la organización turística. } \\
\text { identificación de atractivos turísticos de la } \\
\text { localidad y el estado, programa de animación y } \\
\text { recreación en un hotel y restaurante e } \\
\text { identificación de plan de mercadotecnia de las } \\
\text { empresas, cada proyecto desarrollado con un } \\
\text { proceso metodológico. }\end{array}$ \\
\hline Diseño metodológico & $\begin{array}{l}\text { Estructura metodológica y capítulos donde cada } \\
\text { unidad de competencia involucra a la temática de } \\
\text { acuerdo con sus contenidos. }\end{array}$ \\
\hline Producto final de aprendizaje & $\begin{array}{l}\text { Entrega de trabajo por escrito y exposición de la } \\
\text { investigación hecha de cómo se encuentran } \\
\text { estructuradas organizacionalmente las empresas } \\
\text { turísticas objeto de estudio a partir de la aplicación } \\
\text { de una investigación con pasos metodológicos y el } \\
\text { uso del modelo de la Asociación Americana de } \\
\text { Psicología (APA), y hacer un contraste de lo } \\
\text { teórico con la práctica. }\end{array}$ \\
\hline
\end{tabular}




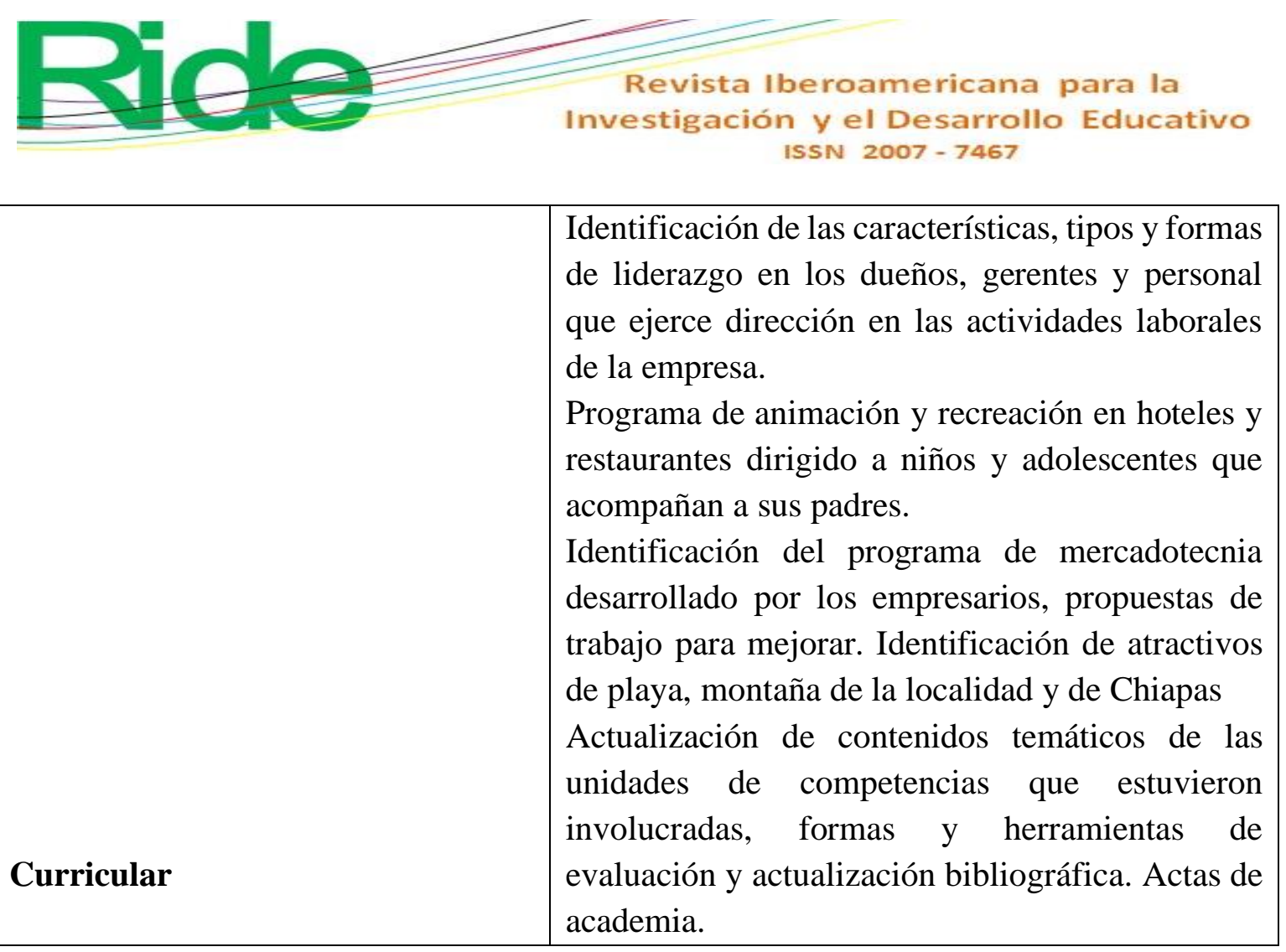

Fuente: Elaboración propia

El esquema desarrollado del sexto al séptimo semestre se determinó por el avance y maduración del proceso cognitivo y metacognitivo del estudiante. 


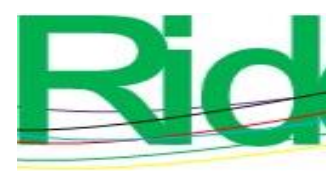

Revista Iberoamericana para la Investigación y el Desarrollo Educativo ISSN 2007 - 7467

Tabla 3. Esquema de trabajo desarrollado en sexto y séptimo semestre

\begin{tabular}{|c|c|}
\hline Objetivo & $\begin{array}{l}\text { Intervención y diseño de productos } \\
\text { turísticos. }\end{array}$ \\
\hline Materias involucradas en el proyecto & $\begin{array}{l}6^{\circ} .^{\circ} \text { semestre: gestión de alojamiento, } \\
\text { desarrollo turístico sustentable, marco legal } \\
\text { de la empresa turística, sistema de } \\
\text { información de la mercadotecnia turística. } \\
7 .^{\circ} \text { semestre: administración estratégica, } \\
\text { planeación del espacio turístico, }_{\text {formulación y evaluación de proyectos }} \\
\text { turísticos, mercadotecnia de servicios } \\
\text { turísticos. }\end{array}$ \\
\hline Objeto de estudio & $\begin{array}{l}\text { Comunidades rurales que tienen } \\
\text { restaurantes y hoteles ubicadas en reservas } \\
\text { naturales que desarrollan actividades } \\
\text { turísticas sustentables. }\end{array}$ \\
\hline Temas de estudio & $\begin{array}{l}6 .^{\circ} \text { semestre } \\
\text { Desarrollo turístico sustentable: análisis } \\
\text { socioambiental, evaluación del impacto } \\
\text { ambiental de los proyectos turísticos, local. } \\
\text { Gestión de alojamiento: identificar uso de } \\
\text { software y estructuras de operatividad. } \\
\text { Marco legal: constitución jurídica de la } \\
\text { empresa, tipo de sociedad. } \\
\text { Sistema de información de } \\
\text { mercadotecnia: estudio de mercado. } \\
7 .{ }^{o} \text { semestre } \\
\text { Administración estratégica: elaboración de } \\
\text { un plan de planear, hacer, verificar y actuar } \\
\text { terminado en un programa de calidad. } \\
\text { Planificación del espacio turístico: describir } \\
\text { el proceso de desarrollo turístico sustentable } \\
\text { de una localidad desde un enfoque de la } \\
\text { planificación del espacio físico subregional. } \\
\text { Mercadotecnia de servicios turísticos: } \\
\text { diseño de estrategias de comercialización de } \\
\text { productos y servicios turísticos de una } \\
\text { comunidad. } \\
\text { Formulación y evaluación de proyectos } \\
\text { turísticos: análisis económico-financiero de }\end{array}$ \\
\hline
\end{tabular}




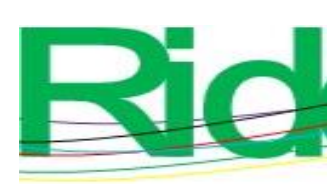

Revista Iberoamericana para la Investigación y el Desarrollo Educativo ISSN 2007 - 7467

\begin{tabular}{|c|c|}
\hline & $\begin{array}{l}\text { inversión en materia turística que le permita } \\
\text { visualizar oportunidades y tomar decisiones }\end{array}$ \\
\hline Diseño metodológico & $\begin{array}{l}\text { Estructura metodológica y capítulos donde } \\
\text { cada unidad de competencia involucra a la } \\
\text { temática de acuerdo con sus contenidos. }\end{array}$ \\
\hline Producto final aprendizaje & $\begin{array}{l}\text { Paquetes turísticos diseñados de acuerdo } \\
\text { con los contextos investigados que } \\
\text { contengan un plan estratégico, estudio de } \\
\text { mercado, programa de cuidado del medio } \\
\text { ambiente y elaboración de un programa de } \\
\text { marketing. }\end{array}$ \\
\hline Curricular & $\begin{array}{l}\text { Actualización de contenidos temáticos de } \\
\text { las unidades de competencias que } \\
\text { estuvieron involucradas, formas y } \\
\text { herramientas de evaluación y actualización } \\
\text { bibliográfica. Actas de academia. }\end{array}$ \\
\hline
\end{tabular}

Fuente: Elaboración propia

Se desarrolló una secuencia didáctica, que planeó y organizó las actividades académicas basada en el modelo de Alfonzo (citado en Feo, 2010), el cual está compuesto por tres momentos, el de inicio, de desarrollo y el de cierre. 
Tabla 4. Diseño de estrategia didáctica

\begin{tabular}{|c|c|c|}
\hline Secuencia didáctica & Recursos y medios & Estrategia de evaluación \\
\hline $\begin{array}{l}\text { Momento de inicio: } \\
\text { exposición de la estructura } \\
\text { del proyecto integrador: } \\
\text { objetivos de aprendizaje de } \\
\text { cada materia, misión, } \\
\text { visión, actividades a } \\
\text { desarrollar en las empresas } \\
\text { o comunidades, productos } \\
\text { a entregar y programación } \\
\text { para fecha de inicio y } \\
\text { término del estudio. }\end{array}$ & $\begin{array}{l}\text { Exposición del diseño por } \\
\text { medio de diapositivas a los } \\
\text { estudiantes por cada uno de } \\
\text { los docentes participantes. }\end{array}$ & $\begin{array}{l}\text { Preguntas y respuestas. } \\
\text { Lluvia de ideas para } \\
\text { determinar la compresión de } \\
\text { las ideas. } \\
\text { Presentación para asesorías } \\
\text { de avances y supervisión de } \\
\text { actividades. }\end{array}$ \\
\hline $\begin{array}{l}\text { Momento de desarrollo: } \\
\text { formación de equipos de } \\
\text { trabajo. } \\
\text { Visitas de trabajo a las } \\
\text { empresas y comunidades. }\end{array}$ & $\begin{array}{l}\text { Listado de equipos de } \\
\text { trabajo formados por } \\
\text { afinidad. } \\
\text { Fichas de observación para } \\
\text { registros. }\end{array}$ & $\begin{array}{l}\text { Registro de todos los } \\
\text { equipos de trabajo } \\
\text { Lista de cotejo. } \\
\text { Guías de observación. }\end{array}$ \\
\hline $\begin{array}{l}\text { Asesorías académicas por } \\
\text { parte de los docentes, dos } \\
\text { veces por semana. } \\
\text { Reuniones de trabajo de } \\
\text { docentes una vez por } \\
\text { semana para conocer } \\
\text { avances y problemáticas. } \\
\text { Tres visitas de supervisión } \\
\text { de docentes para asesoría } \\
\text { en campo. }\end{array}$ & $\begin{array}{l}\text { Avances del trabajo } \\
\text { documental y presentación } \\
\text { de productos realizados, } \\
\text { trípticos, diapositivas, } \\
\text { videos, audios, anuncio de } \\
\text { radio, maquetas, lonas, etc. } \\
\text { Minutas de trabajo de } \\
\text { reunión de docentes y } \\
\text { acuerdos para cumplimiento } \\
\text { de objetivos. } \\
\text { Bitácora de registro de } \\
\text { visitas. }\end{array}$ & $\begin{array}{l}\text { Hoja de análisis de tareas. } \\
\text { Descripciones } \\
\text { Avances logrados } \\
\text { Avances en las actividades } \\
\text { de campo. }\end{array}$ \\
\hline $\begin{array}{l}\text { Momento de cierre: } \\
\text { presentación del proyecto } \\
\text { integrador. }\end{array}$ & $\begin{array}{l}\text { Documental: presentación } \\
\text { de trabajo final por equipos } \\
\text { en el aula. } \\
\text { De campo: cierre de } \\
\text { actividades en la empresa o } \\
\text { comunidad. }\end{array}$ & $\begin{array}{l}\text { Evaluación de rúbrica de } \\
\text { presentación del trabajo } \\
\text { final y de exposición de } \\
\text { acuerdo con los objetivos } \\
\text { curriculares de cada materia. } \\
\text { Evaluación de todos los } \\
\text { docentes involucrados. }\end{array}$ \\
\hline
\end{tabular}




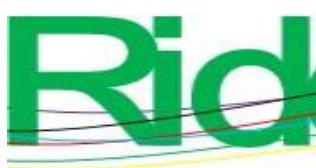

Revista Iberoamericana para la
Investigación y el Desarrollo Educativo
ISSN $2007-7467$

- Solicitud por escrito para realizar una visita de acercamiento entre el empresario y el docente.

- $\quad$ Presentación del proyecto (objetivo, estructura, periodo de trabajo).

- Visita del docente y estudiantes a la empresa para determinar área de trabajo a intervenir y toma de decisiones en conjunto con el empresario.

- $\quad$ Planeación de actividades en áreas programadas.

- Visita de supervisión de los docentes involucrados de acuerdo con objetivos de las asignaturas.

- Presentación de resultados en el salón de clases con la presencia de los empresarios, alumnos y docentes.

- $\quad$ Entrega a los empresarios de resultados y productos que se originaron en la actividad realizada.

\section{Proceso curricular}

Desde la vinculación teoría-práctica, de enfoque problematizador, sistémico, complejo y holístico que permitiera que el plan de estudio de la licenciatura fuera evaluado de manera sistemática y enriquecer así contenidos temáticos, referencias bibliográficas que alimenten las líneas de investigación, revisión del perfil de egreso.

Figura 4. Evaluación curricular
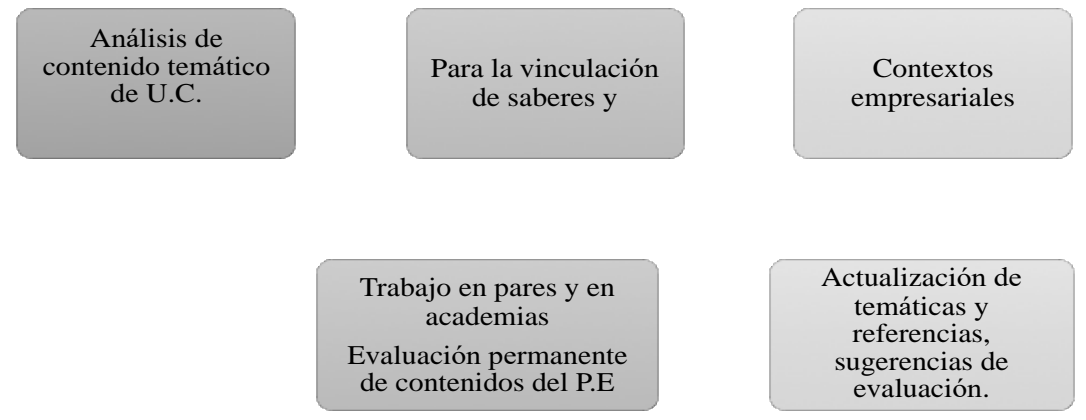

Fuente: Elaboración propia

La recolección de datos fue producto de una reflexión y organización previa sobre la opinión de los estudiantes. Los hallazgos emergieron de los datos obtenidos y se presentan 


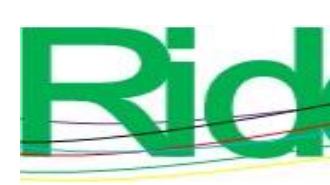

Revista Iberoamericana para la Investigación y el Desarrollo Educativo ISSN 2007 - 7467

de manera esquemática para dar una explicación más clara sobre las categorías usadas, con la finalidad de revelar el significado del proceso de aprendizaje en el estudiante.

\section{Resultados}

Los resultados obtenidos de cada uno de los proyectos integradores fueron diversos. En cada uno se trabajaron temáticas diferentes. Los datos sociodemográficos que se presentan son de 136 estudiantes de la Facultad de Ciencias de la Administración C-IV, Tapachula, Chiapas, de la Unach. Se formaron 26 equipos de trabajo. La edad promedio de los estudiantes fue de 18 a 24 años. Respecto al cuestionario aplicado a los estudiantes al final de toda la intervención didáctica, las respuestas fueron concentradas en la tabla 5.

Tabla 5. Resultados del cuestionario

\begin{tabular}{|l|l|}
\hline Temática & \multicolumn{1}{|c|}{ Opiniones más frecuentes } \\
\hline $\begin{array}{l}\text { Contenidos claros y precisos de las } \\
\text { asignaturas }\end{array}$ & $\begin{array}{l}\text { Después de haber desarrollado sus actividades } \\
\text { asignadas, los contenidos quedaron más claros y } \\
\text { precisos. }\end{array}$ \\
\hline $\begin{array}{l}\text { Herramientas de aprendizajes } \\
\text { utilizadas }\end{array}$ & $\begin{array}{l}\text { Al inicio tenían muchas confusiones para } \\
\text { realizar las tareas; además, trabajar con varias } \\
\text { asignaturas integradas, era la primera vez } \\
\text { utilizando tantas herramientas didácticas para el } \\
\text { seguimiento y evaluación. }\end{array}$ \\
\hline El objetivo del aprendizaje obtenido & $\begin{array}{l}\text { Consideran que fue conseguido, al tener la } \\
\text { visión completa de cómo las unidades de } \\
\text { competencias articulan todo el conocimiento y } \\
\text { ellos pueden movilizarlo para obtener un } \\
\text { producto. }\end{array}$ \\
\hline $\begin{array}{l}\text { Pertinencia de la evaluación con un } \\
\text { proyecto integrador }\end{array}$ & $\begin{array}{l}\text { Consideran que los criterios se visualizaban muy } \\
\text { difíciles de conseguir, pero, al ir desarrollando } \\
\text { sus actividades, se percataron que iban } \\
\text { cumpliendo con ellos, y además se les sirvió para } \\
\text { fortalecer su habilidad de presentar resultados en } \\
\text { público poco común, esto es, los empresarios. }\end{array}$ \\
\hline $\begin{array}{l}\text { Estructuración metodológicas y } \\
\text { asesorías }\end{array}$ & $\begin{array}{l}\text { Un poco confusa al inicio, pero gracias a la } \\
\text { asesoría y al seguimiento las dudas se fueron } \\
\text { disipando. }\end{array}$ \\
\hline $\begin{array}{l}\text { Consideran que el empresario estuvo al inicio } \\
\text { escéptico sobre lo que se haría, pero la } \\
\text { supervisión y comunicación de los docentes }\end{array}$ \\
\hline
\end{tabular}




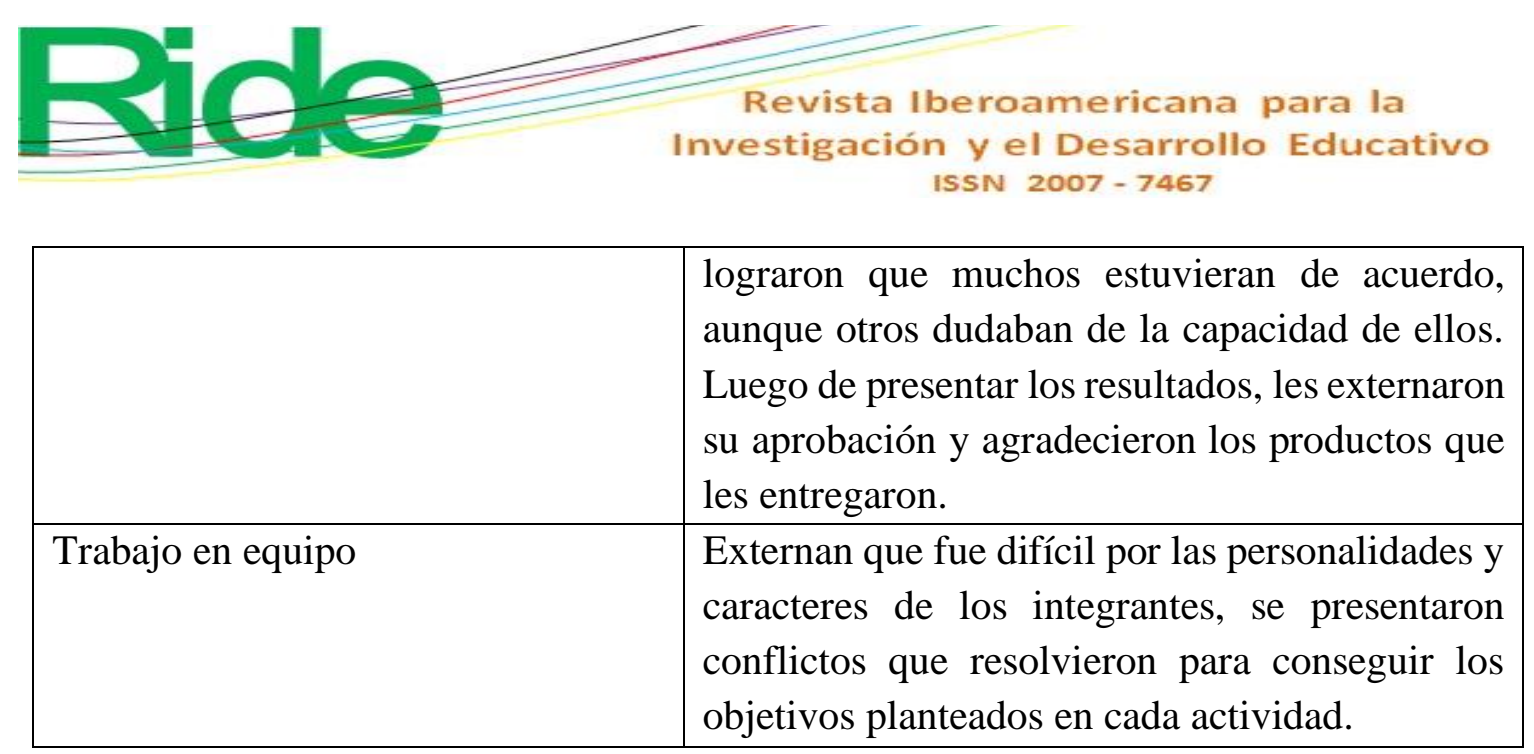

Fuente: Elaboración propia

El resultado de las opiniones fue satisfactorio para los maestros, pues implicó un trabajo de planeación, asesorías, observación y seguimiento más puntual tanto en el aula como en el campo. Cabe destacar que la evaluación fue muy satisfactoria por los productos obtenidos y el esfuerzo realizado por los estudiantes, y además se obtuvo sin presiones de ninguna índole. Las opiniones generales más relevantes vertidas en el cuestionario por los estudiantes se encuentran en la tabla 6.

Tabla 6. Opiniones generales

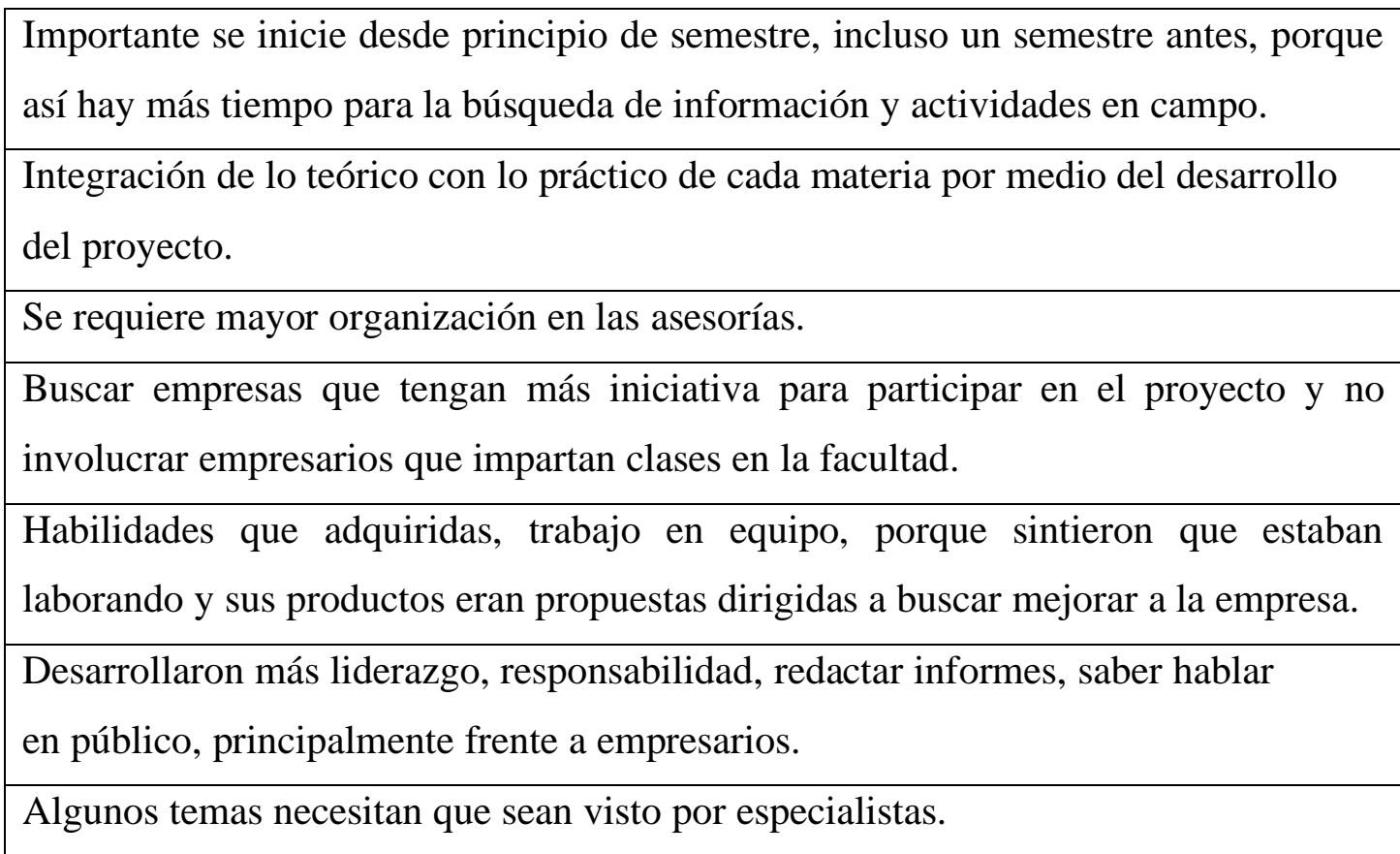

Fuente: Elaboración propia

Respecto a las herramientas didácticas utilizadas, se encuentran la lista de cotejo y la rúbrica para trabajos documentales y la exposición para poder ponderar el aprendizaje obtenido. 


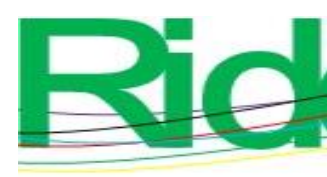

Revista Iberoamericana para la Investigación y el Desarrollo Educativo ISSN 2007-7467

La lista de cotejo fue utilizada con el objetivo de evaluar las actividades y tareas, comportamiento, habilidades, actitudes en el proceso de aprendizaje desde el nivel de logro o de ausencia de algunos criterios.

Tabla 7. Lista de cotejo

\begin{tabular}{|l|c|c|}
\hline Criterios de evaluación por equipos de trabajo & Sí & No \\
\hline Realizó sus actividades en tiempo y forma & 25 & 1 \\
\hline Las tareas contienen todos los criterios solicitados & 22 & 3 \\
\hline Creatividad, innovación, utilidad del producto final & 19 & 7 \\
\hline Organización, responsabilidad y puntualidad & 17 & 8 \\
\hline Actitud de servicio y trabajo en equipo & 24 & 2 \\
\hline
\end{tabular}

Fuente: Elaboración propia

Cada uno de estos criterios utilizados permitió observar el avance de cada equipo, desde la planeación de sus actividades hasta la manera de realizar la búsqueda de información, el liderazgo asumido por uno de los integrantes y la manera de conducir el grupo, así como la habilidad para asumir responsabilidades y tomar decisiones en las problemáticas presentadas. La mayoría de los productos entregados cumplieron con las expectativas y algunos otros las superaron.

Respecto a la rúbrica, se definieron varios criterios para el documento por escrito y para la presentación verbal, todo lo cual se les dio a conocer para que fuera una guía de trabajo y de autoevaluación de cumplimiento.

Los criterios para el trabajo escrito fueron los puestos a continuación: Contenido del documento (referencias teóricas del desarrollo de los capítulos, formato APA); Comprensión (congruencia y coherencia en la comprensión e interconexiones disciplinarias); Estilo y forma (correcto uso de la ortografía y gramática), y Información complementaria (mapas, cuadros, tablas, gráficas, imágenes, cuestionarios, etc.). En la tabla 8 se concentran los resultados correspondientes. 


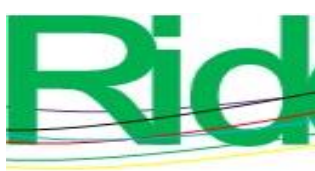

Revista Iberoamericana para la Investigación y el Desarrollo Educativo ISSN $2007-7467$

Tabla 8. Criterios de trabajo cumplidos por equipo de trabajo

\begin{tabular}{|l|c|c|c|}
\hline Trabajo escrito & Cumplió & Intermedio & Novato \\
\hline Presentación del proyecto & 26 & 0 & 0 \\
\hline Contenido del documento & 18 & 5 & 3 \\
\hline Comprensión & 20 & 3 & 3 \\
\hline Estilo y forma & 15 & 6 & 5 \\
\hline Información complementaria & 22 & 3 & 1 \\
\hline
\end{tabular}

Fuente: Elaboración propia

Los criterios a evaluar en la exposición de resultados fueron los siguientes; Organización de la información (de acuerdo con la estructura acordada en los capítulos), Contenidos del tema (acorde con el tema de investigación, actualidad de la información y la conexión con la actividad desarrollada en la empresa); Recursos tecnológicos (cañón proyector, computadora, audio, mapas conceptuales, pizarrón, cartulinas, entre otros), y Presentación de imagen (utilización de uniformes, caracterización, orden, limpieza, puntualidad).

Tabla 9. Criterios de evaluación para la presentación de la exposición por equipos

\begin{tabular}{|l|c|c|c|}
\hline $\begin{array}{l}\text { Presentación } \\
\text { verbal }\end{array}$ & Cumplió & Intermedio & Novato \\
\hline $\begin{array}{l}\text { Organización de la } \\
\text { información }\end{array}$ & 22 & 3 & 1 \\
\hline $\begin{array}{l}\text { Contenido del tema } \\
\text { y manejo grupo }\end{array}$ & 20 & 5 & 1 \\
\hline $\begin{array}{l}\text { Recursos } \\
\text { tecnológicos y } \\
\text { didácticos }\end{array}$ & 24 & 1 & 1 \\
\hline $\begin{array}{l}\text { Presentación de } \\
\text { imagen personal }\end{array}$ & 25 & 1 & 0 \\
\hline
\end{tabular}

Fuente: Elaboración propia

Los resultados obtenidos en la presentación del trabajo escrito indican que $69 \%$ cumplió de manera completa; 31 \% presentó ausencia de elementos como objetivos claros, faltas de ortografía, entre otros. Las asesorías constantes de los docentes fue indispensable 


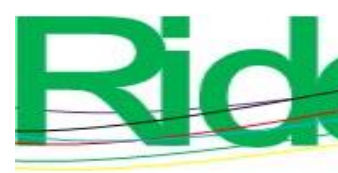

Revista Iberoamericana para la Investigación y el Desarrollo Educativo ISSN $2007-7467$

para que el estudiante obtuviera los conocimientos necesarios. Respecto a las exposiciones hechas por equipo, destaca la creatividad de los estudiantes, que aprovecharon todos los recursos a su alcance y otros fueron creados, gracias a lo cual hicieron un producto consistente y comerciable. La opinión de los empresarios fue muy satisfactoria al presenciar los resultados. Cabe destacar que uno de ellos fue adoptado por un restaurante, a través de un plan de negocio, lo que hizo que bajaran recursos, remodelaran la cocina, el área de restaurante e incorporaran una sala de usos míltiples.

Por último, describir cada estrategia didáctica utilizada en la implementación de los proyectos integradores ha permitido conocer la articulación del aprendizaje en el estudiante, desde la capacidad de percibir hasta experimentar los contextos que lo rodean y cómo regular, organizar y construir sus propios saberes. Su visión del aprendizaje se vuelve más holística porque analizan el conjunto de los conocimientos vertidos y sus múltiples interrelaciones, lo cual sin duda apoya a su formación profesional.

\section{Discusión}

Los resultados que se presentan constituyen un acercamiento válido para conocer el proceso de aprendizaje del universitario a través de los proyectos integradores. El desafío fue para docentes y estudiantes de la Facultad de Ciencias de la Administración. Se logró describir las estrategias didácticas y se hizo el desarrollo metodológico para la articulación de los conocimientos cognitivos y metacognitivos. Con lo obtenido se determinó que el trabajo académico es muy fructífero para ambos actores de este proceso. Se crearon las condiciones adecuadas y las estrategias fueron adaptadas a los contextos donde el estudiante aplicaría los conocimientos obtenidos. La vinculación permitió que su intervención y movilización de conocimientos alcanzara una destacada evaluación académica. La satisfacción del estudiante fue evidente; los comentarios vertidos tanto por los docentes como por el sector empresarial igualmente apuntan hacia esa dirección.

Otra consecuencia fue el proceso de actualización de los contenidos del plan de estudio a través de la planeación didáctica y el trabajo en academias hecho por el grupo de docentes participantes. Los procesos de retroalimentación se volvieron indispensables para todos. El proceso no estuvo exento de resistencia al cambio por parte de docentes y estudiantes: en los primeros, la falta de tiempo por tener otras responsabilidades, los estudiantes porque sentían tener poco tiempo y muchas actividades que realizar, confusión y 


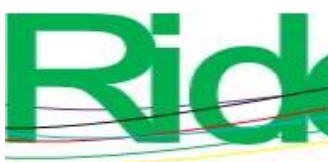

Revista Iberoamericana para la
Investigación y el Desarrollo Educativo
ISSN $2007-7467$

creían que el avance era poco; al final, sin embargo, descubrieron que se trabajó de manera puntual y que los productos obtenidos respondieron a las necesidades sentidas.

\section{Proceso de cognición}

Los conocimientos cognitivos que se articularon con los proyectos integradores se cristalizaron principalmente en el comportamiento y las actitudes que asumían los estudiantes. Bandura (citado en Alegre, 2014) denomina a esto factores mentales cognitivos, concepto que forma parte de su teoría del aprendizaje social. Y los clasifica en tres procesos fundamentales:

- $\quad$ Adquisición: donde presta atención y percibe los elementos más importantes.

- $\quad$ Referencia: recordar mediante imágenes o palabras lo que hizo el modelo.

- Ejecución: transforma lo aprendido en acción para obtener un resultado (Bandura, 1997, citado en Alegre, 2014).

Figura 5. El proceso de aprendizaje cognitivo

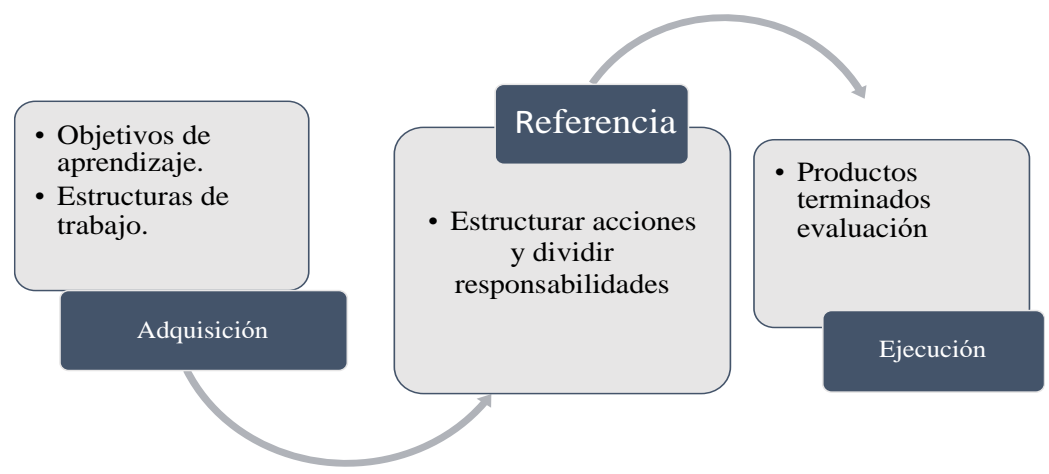

Fuente: Elaboración propia con base en Bandura (1997, citado en Alegre, 2014)

\section{Proceso metacognitivo}

Autores como Brown (1987, citado en Torres, 2019) y Schraw y Moshman (1995, citados en Torres, 2019) refieren que las estrategias metacognitivas son actividades de autorregulación que ayudan a controlar el pensamiento o el aprendizaje, y los tres subprocesos que las conforman son: la planeación, la cual se basa en la toma de decisiones, los objetivos y la organización; la contextualización, que consiste en la elaboración del contenido y espacio, y la revisión, la cual reside en la evaluación o corrección del producto. 


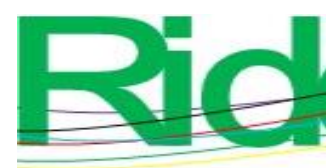

Revista Iberoamericana para la Investigación y el Desarrollo Educativo ISSN 2007 - 7467

Este conocimiento se desarrolló en todo el proceso de ejecución, pero fue más relevante en los productos obtenidos.

Tabla 10. Proceso de aprendizaje metacognitivo

\begin{tabular}{|c|c|}
\hline Operación & Actividad proyecto integrador \\
\hline Planeación & $\begin{array}{l}\text { Define el objetivo que quiere alcanzar en cada una de las } \\
\text { asignaturas y toma la decisión de qué producto será el que integre } \\
\text { todos los elementos requeridos por el proyecto investigación } \\
\text { documental. Organización y designación de actividades del } \\
\text { equipo de trabajo. } \\
\text { Plan de trabajo de mercadotecnia, planeación estratégica, } \\
\text { capacitación, alimentos y bebidas, atención al cliente, entre otros. } \\
\text { Investigación de campo. Determina con visitas de observación, } \\
\text { contacto con empresarios, líderes comunales, instituciones } \\
\text { gubernamentales. }\end{array}$ \\
\hline Contextualización & $\begin{array}{l}\text { Elaboración del producto turístico en la comunidad, por ejemplo, } \\
\text { rutas turísticas en coordinación con instituciones } \\
\text { gubernamentales. } \\
\text { Elaboración de paquetes turísticos de temporada que incluyan } \\
\text { alojamiento, alimentos y transporte. } \\
\text { Programa publicitario en radio, elaboración de videos, lonas } \\
\text { publicitarias de ubicación del destino, programas de capacitación } \\
\text { administrativo, manejo de alimentos y bebidas, carta menú y } \\
\text { atención al cliente, programa de reciclado de basura, entre otros. } \\
\text { Determinar tiempo en qué se realizará la actividad, quiénes serán } \\
\text { los participantes y en qué espacio podrá desarrollarse la acción } \\
\text { requerida. }\end{array}$ \\
\hline Revisión & $\begin{array}{l}\text { Se establece desde la asesoría constante, docente, empresarios y } \\
\text { retroalimentación de los procesos para corregir desviaciones. } \\
\text { Supervisión y evaluación de avances programados por cada } \\
\text { miembro del equipo de trabajo formado. }\end{array}$ \\
\hline
\end{tabular}




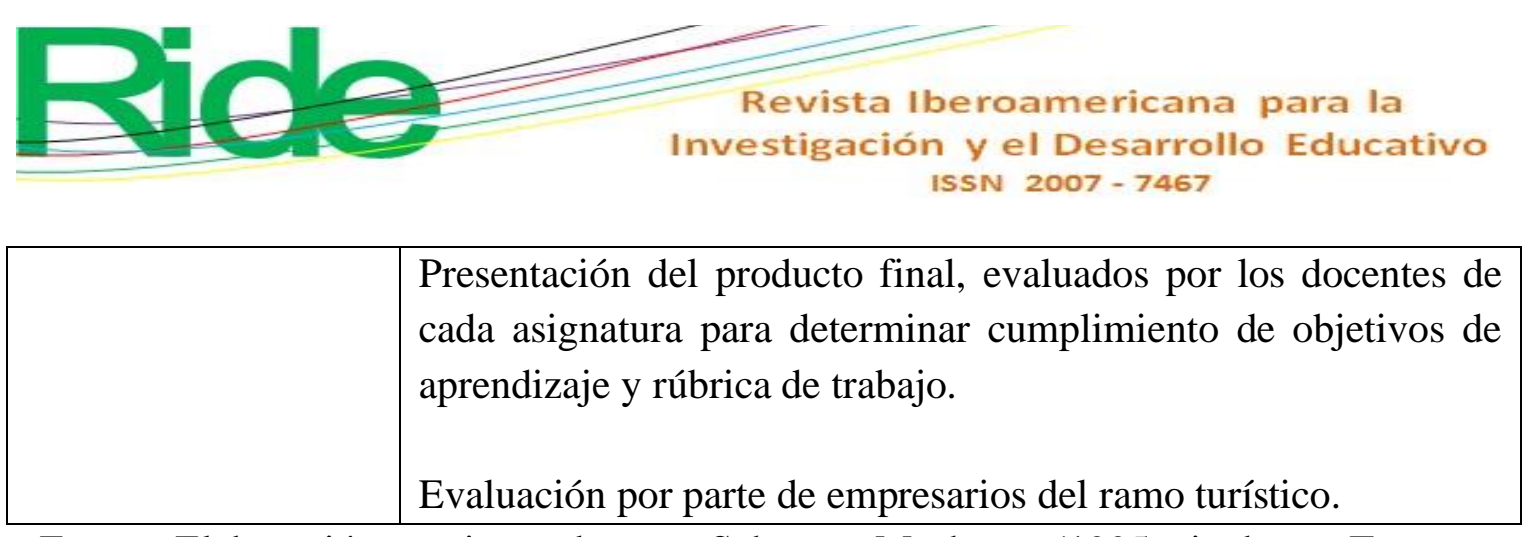

Fuente: Elaboración propia con base en Schraw y Moshman (1995, citados en Torres,

2019)

En este proceso, los estudiantes regularon su aprendizaje con mayor precisión y alcanzaron los objetivos esperados. Lo más relevante fue dirigir algunos procesos de manera autónoma, resolver problemas con estrategias implementadas y el desarrollo de un aprendizaje significativo. La evaluación final para la presentación de los resultados fue ante un claustro de docentes, empresarios y miembros de la comunidad, quienes calificaron que los productos cumplieran con las características deseables.

\section{Conclusiones}

Cada día es más complejo el proceso de enseñanza. Las nuevas tecnologías son instrumentos muy útiles a la hora de transmitir los conocimientos, pero también pueden ser distractores o simuladores de aprendizaje. El docente tiene que estar en constante innovación sobre el uso de estrategias didácticas que aseguren en el estudiante su formación. Determinar el aprendizaje en los estudiantes es sin duda una tarea muy diversa debido a los contextos familiares, económicos y académicos que lo rodean, y son factores que inciden de manera directa en su rendimiento.

Existe un sinnúmero de estrategias didácticas que aseguran en mayor o menor medida el aprendizaje y todas son válidas. En este estudio, la implementación de los proyectos integradores se consideró lo más idóneo. Estos, los proyectos integradores, se constituyeron en un acercamiento al complejo fenómeno de la enseñanza y aprendizaje, se convirtieron en una herramienta que puede ser utilizada por aquellos individuos involucrados en la tarea de enseñar. En la figura 6 se lograron articular conceptualmente los procesos cognitivos y metacognitivos que se observaron a lo largo de este estudio. 


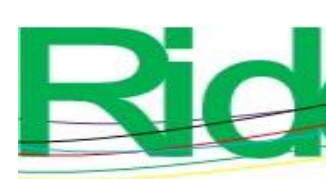

Revista Iberoamericana para la Investigación y el Desarrollo Educativo ISSN $2007-7467$

Figura 6. Proceso de articulación

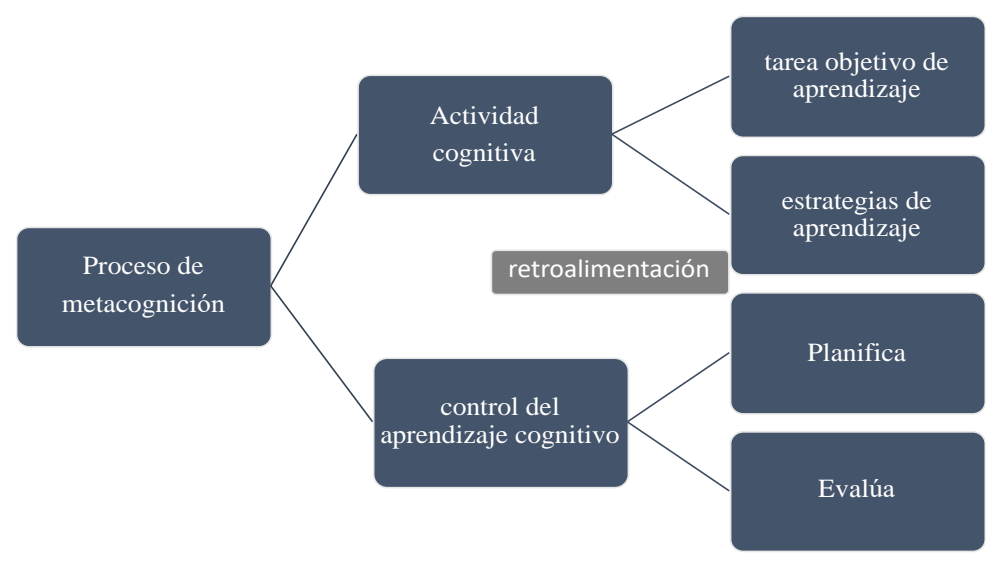

Fuente: Elaboración propia

En conclusión, el proceso de aprendizaje articulado a los proyectos integradores trae consigo componentes cualitativos que pueden ser observados en la actitud de los estudiantes frente la actividad en clase y los trabajos asignados, desde su personalidad, reflejado en su sentido de responsabilidad, motivación e interés por aprender.

Respecto al proceso de la enseñanza en el docente, la planeación didáctica y la alineación a los objetivos del plan de estudio fue relevante, de acuerdo con los resultados obtenidos, y, además, la interacción con el grupo de docentes permitió un mayor acercamiento para conseguir que el semestre tuviera una dinámica totalmente fuera de lo común.

La estructuración de un portafolio de evidencias permitió una valoración objetiva de los trabajos realizados. La motivación para emprender el trabajo por parte del estudiante y el docente, la vinculación hecha con el sector empresarial de la actividad turística, la aceptación de los resultados obtenidos y, en todos los casos, la ejecución de las acciones en beneficio de estos son algunos de los beneficios de esta experiencia. El aseguramiento del conocimiento se da de diversas maneras y los proyectos integradores son parte de esta gran gama de posibilidades. 


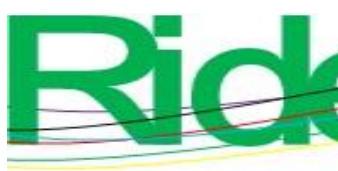

Revista Iberoamericana para la Investigación y el Desarrollo Educativo ISSN 2007-7467

\section{Referencias}

Alegre, A. (2014). Autoeficacia académica, autorregulación del aprendizaje y rendimiento académico en estudiantes universitarios iniciales. Propósitos y Representaciones, 2(1), 79-120. Recuperado de http://dx.doi.org/10.20511/pyr2014.v2n1.54.

Bartone, R. y Sandoval. A. (2014). Perfil metacognitivo en estudiantes universitarios. Investigación y Posgrado, 29(1),129-149. Recuperado de http://www.redalyc.org/articulo.oa?id=65848192006.

Feo, R. (2010). Orientación básica para el diseño de estrategias didácticas. Tendencias Pedagógicas, (16), 7-17. Recuperado de https://repositorio.uam.es/bitstream/handle/10486/5273/33795_2010_16_13.pdf.

Fortoul, M. (2008). La concepción de la enseñanza según los estudiantes del último año de la licenciatura en Educación Primaria en México. Perfiles Educativos, 30(119), 7289. Recuperado de http://www.scielo.org.mx/pdf/peredu/v30n119/v30n119a5.pdf.

Hernández, F. y Martínez, P. (2008). La formación en competencias en educación superior: un nuevo factor de calidad en el contexto multicultural. En Soriano, E. (coord.). Educar para la ciudadanía intercultural y democrática. Madrid, España: La Muralla.

Juan, N y Pérez, A. (mayo de 2017). Ponencia: Proyecto integrador; con un enfoque de educación y cultura ambiental para el desarrollo de actividades turísticas en el ejido El Águila, municipio de Cacahoatan, Chiapas, Universidad Autónoma de Querétaro, $7^{\circ}$ Congreso Internacional Turismo y Economía, Campus Tequisquiapan, Querétaro, México.

López, M. (2016). Perfiles de participación en la red de los estudiantes universitarios y sus repercusiones en el aprendizaje. Revista de Educación a Distancia, 49(6). Recuperado de http://www.redalyc.org/articulo.oa?id=5474536201.

Organización Mundial del Turismo [OMT]. (2018). Resultados de la actividad turística. México: Subsecretaría de Planeación y Política Turística. Recuperado de http://www.datatur.sectur.gob.mx/SitePages/versionesRAT.aspx.

Sandoval, A. (2005). Metacognición y rendimiento académico. (trabajo de grado no publicado). Universidad Complutense de Madrid, España.

Secretaría de Turismo [Sectur]. (2019). Datatur enero. México: Subsecretaría de Planeación y Política Turística. Recuperado de http://www.datatur.sectur.gob.mx/SitePages/versionesRAT.aspx. 

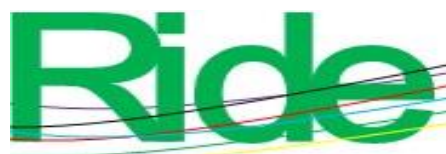

Revista Iberoamericana para la Investigación y el Desarrollo Educativo

ISSN $2007-7467$

Terrádez, M. (2007). Profe, yo no quiero salir a la pizarra. Sobre tímidos, introvertidos y estilos de aprendizaje. Ponencia presentada en el I Congreso Internacional de Lenguas, Literatura y Cultura Española. Valencia, del 17 al 19 de mayo de 2007. Recuperado de https://dialnet.unirioja.es/servlet/articulo?codigo=2341109.

Torres, G. (2019). Proceso de regulación metacognitiva en la adquisición de hábitos alimenticios en los estudiantes de grado séptimo del Colegio de la Sagrada Familia de Montería. (tesis de maestría). Universidad Autónoma de Manizales, Colombia.

Universidad Autónoma de Chiapas [Unach]. (2010). Modelo Educativo y de la Universidad Autónoma de Chiapas. Tuxtla Gutiérrez, México: Universidad Autónoma de Chiapas.

Universidad Autónoma de Chiapas [Unach]. (2014). Modelo Educativo y Académico. Tuxtla Gutiérrez, México: Universidad Autónoma de Chiapas.

Universidad Autónoma de Chiapas. (2019a). ler. Informe de actividades. Rectoría 20182022. Tuxtla Gutiérrez, México: Universidad Autónoma de Chiapas. Recuperado de https://www.unach.mx/images/documentos/2019/1er_Informe_Rectoria_20182022.pdf. 